\title{
Social and economic well-being in the conditions of the urban space: the evolution of methodological approaches in the historical urban studies
}

\author{
Ilya Ageev ${ }^{1, a}$, Anastasia Nikolaeva ${ }^{1}$, Peter Rumyantsev $^{2}$ \\ ${ }^{1}$ National Research Tomsk Polytechnic University, Lenin Avenue, 30, Tomsk 634050, Russia \\ ${ }^{2}$ National Research Tomsk State University Lenin Avenue, 36, Tomsk 634050, Russia
}

\begin{abstract}
A city as a type of a human settlement is characterized by high population density, welldeveloped infrastructure, comfortable living conditions. However, a city is a source of social problems due to high population density, limited resources and conflicts between indigenous population and newcomers. The article analyzes the development of research about the city, provides an assessment of the scope of the historical urban studies in the development of solutions to contemporary problems of urban space. Methodological resource of historical urban studies allows fully exploring the city as a set of historically interconnected spaces and social processes. The analysis of the problem field of historical urban studies at various stages of its formation allowed tracing the evolution of ideas about the city as an object of scientific knowledge, to identify future prospects of research on conditions of Russian urban development, to improve the comfort of living in them.
\end{abstract}

\section{Introduction}

Cities are diverse types of human settlements, transforming under the influence of economic and technical progress on such parameters as the shape, function, a legal status and a social structure of the population. At all times, cities have differed from the surrounding area with their high density and other kind of activity of the population.

Research relevance of the problems of modern urban spaces is connected with the need for timely solutions of such issues as overcrowding of cities, overloaded communications, ethnic and social conflicts, high cost of living, low efficiency of management, lack of resources. However, at each previous stage of development inhabitants of the cities also had to solve problems to improve urban living conditions. By eliminating the infrastructure or the social problems from their cities, their residents received new ones instead.

The effects of modernization and economic transformations are added to a range of these issues. As a result, the cities with similar geographic and economic potential become the holders of unequal indicators of information, investment and tourist attractiveness, different development levels of engineering and social infrastructure. In post-industrial society, these indicators of the city's economic potential assessment are undeniably more significant than previously used such as the proximity of raw materials and resources, the availability of labor force.

\section{Materials and method}

The scientific significance of the article is to find a new aspect of the urban studies, which maintains the continuity of the traditional research on cities but suggests investigation of the processes that determine the interaction of the urban space and the urban community. For example, the research object should include the work of municipal services, city improvement projects, investment in urban infrastructure, creating the conditions for development of the city's economy and private business, reducing costs arising from the poor quality of the urban environment, etc.

The results of scientific research should be the formation of complex knowledge about the historical development of cities, the factors that determine the quality of infrastructure, investment attractiveness and other factors, for which the city is estimated at the present time. The novelty of this study is the summarizing the theoretical models of modern foreign and domestic research on urban spaces as well as the identification of heuristic resource of this models for the scientific understanding of contemporary urban issues.

The purpose of this article is to identify the methodological resource for the historical urban studies

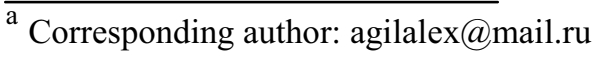


in the development of solutions of contemporary problems of urban space.

The main historiographical sources for the research were works on urban planning, published in Russia and abroad. The methodology is traditional for the historiographical research. It involves the use of comparative analysis and a historical-genetic method.

\section{Results and discussion}

Identifying the causes of today's urban problems and search for possible solutions are in the research area of special scientific discipline - urban studies. The term comes from the economic geography [1], where it means the analysis and study of the problems associated with the functioning of cities. As the area of sociohumanitarian knowledge, urban studies aim at identifying the most common features and urbanization trends, formation of shape and structure of cities, their existence and transformations as a result of technological revolutions and social change.

Urban studies are an interdisciplinary science. Researchers from different disciplines bring to the urban studies their methodology, but consider the city in the narrow sense - only in the context of their scientific field, without referring to the experience of other research models. This problem is typical not only for the interdisciplinary discourse but for intra-historical one [2]. The qualitative breakthrough in urban planning will be possible in the case of integrated research of Cities.

Historical urban studies, as a part of urban studies, consider issues of urban development and functioning in the historical perspective.

D.Ya. Rezun was one of the first Russian researchers who used the term "urban studies" as applied to historical research. He considered it as all city historical research and historiography [3, 22]. This definition eliminates economic and geographical component of urban studies object, which was the inherent generic concept formulated in the socio-economic knowledge. The reason for this difference is likely to become the abundance of accumulated historical knowledge of the city that required a terminological clarification.

In addition to urban studies, historical science and the city interact in such a rapidly developing scientific field, as the history of the city. It is relevant to compare the methodological practices of historical urban studies and the history of the city with a view to distinguishing their subject areas.

The history of the city involves the study of the city as a community of the most active people of their era (managers, politicians, scientists), united by a common space of the city and as a result of the application of their creative and business efforts. Thus, the local history of the city pays the greatest attention to the activities of people living in a town or place, whereby the leading method of this study becomes a locally-historical method $[4 ; 5]$.

The identification of regional historical specificity eliminates the value of the settlement type, as the historian's research interest is not intended at the place and the socio-political phenomena that occur in it [6]. City, a worker's settlement or village, turn into a point on the map, which localize a historical event or phenomenon [7;8]. Today studies of Russian cities largely are realized in three types of historical works. Writing works on urban history most often leads to the popularization of a particular city, demonstrating its uniqueness in the galaxy of other ones [9]. These formfactors are often used by ethnographers.

Another type of urban history, in which attempts are made to go away from the local history component, is the research demonstrating involvement of the city's history in the history of the state, achievements of residents in the implementation of public tasks, their "contribution to the common cause" [10-12].

Finally, the third research experience of urban history is microhistory that reflects global historical patterns in the development of society by using local examples, extracted by the historical specification of the city or locality [13].

In all these algorithms, the subject of scientific research is the human community, while the city defines only the geographical scope of the particular historical work. At the same time, questions about how the city developed in a particular historical period, in terms of the internal connections - both engineering and social, remain without answer. Environment description is undoubtedly present, but it often has the character of fixing the city's status at a particular time.

Description of the living conditions provided by the city, most states full or partial unavailability of infrastructure, lack or low qualification of personnel who are responsible for its development [14]. Thus, the modern historical studies of Russian cities, because of the specificity of the subject and methodology, do not analyze the issues which are in the focus of historical urban studies.

In contrast to urban history, the consideration of the city in the context of historic urban studies suggests that the formation of appearance and structure of cities to a greater extent is under the influence of objective economic and social processes rather than historical persons. Unlike the urban history, historical urban studies translate the idea of exploring the city as a social phenomenon - a specially formed space for life and human activity.

This city is not just a home to the society, it effects intensively the society, creating a different model of interpersonal relationships and changing lifestyles. Modern researchers consider the city as a possible area for their studies, but do not concretize the possible impact of cities on the socio-economic and political relations [15].

In addition, the specificity of the city as an object of historical urban studies is determined by other factors. Not only the economic and social process but increasing volumes of scientific knowledge about the city have a direct impact on urban development.

At the beginning of the 20th century the significant infrastructure improvement of the largest cities contributed inevitably to their further growth. However, the completion of the industrial revolution provided the 
heaps of engineering systems, industrial space exceeding residential development in cities. This practice increased the distance between the man and the nature, leading to environmental problems. By the 1930s, in the European and American industrial city there was no more comfortable life.

The increase in the growth rate of urban population has given rise to social conflicts. In the 1930s, American sociologists from the University of Chicago (Nels Anderson, Ernest Burgess, Ruth Shonle Cavan) among the first initiated studies on the social development in a rapidly growing city. Their joint activities received generalized name of "Chicago School" and laid the foundations of historical urban studies. The first works in this direction were historical reviews on the development of Chicago contemporary to them [16;17].

A further solution of urban problems was interrupted by the events of the World War II. In the second half of the 20th century, the population solved independently these problems in accordance with their financial capabilities. Representatives of the middle class to bought private cars and moved to the suburbs. Big businessmen and investors transferred their plants in the neighborhood of cities, on which authorities imposed fewer requirements for the eco-friendliness of production. The vacated districts have undergone the gentrification and revitalization. Local authorities have contributed, increasing environmental fees and taxes on transport.

The result was a partial unloading of the largest centers of European and American cities from industrial pollution. Cities began to transform from industrial to office and business centers. Specific phenomena of that time were suburbanization, the creation of green areas, integrated public transport systems, the functional evolution of urban areas. Thus, the gentrification process, which began in the middle of the 20th century, involving the scientific community of ecologists and psychologists in the solution of urban problems.

However improving the quality of citizens' life as well as the reorientation of the urban employment to the office or intellectual work has brought a new wave of migration in the late 20 th - early 21 st century. Since then, immigrants were not the villagers from the suburbs, but citizens of other countries and representatives of other cultures. Conflict of identities once again led to an increase in tension in the cities. Today street safety issues, urban and national identity, tolerance are relevant than ever.

The history of the urban environment modernization demonstrates the oscillation amplitude of the comfort level of city life with the increase in population. Complex measures for the improvement of urban infrastructure almost inevitably led to an increase in urban population and the consequent reduction in the level of urban life comfort.

Historical urban studies as the original area of scientific knowledge gained an impulse of the development in international historical science in the first half of the 20th century. Scientific, including historical interpretation of cities also developed in Soviet science in this period but in a different direction. D. Ya.
Rezun well noted the Soviet style of urban historiography. He called it a "production for production's sake", meaning scholastic disputes about "the moment of transition from the manufactory to the small-scale production", etc. instead of focusing on the customer and the market [18]. Only some works of Soviet historians of cities focused on the study of the city structure and not characteristic of its external parameters [19].

Currently, urban issues experience the growth of popularity in Russian and international science due to the growth of cities and the expansion of various topics and methodologies. A number of researchers study the history of individual groups of cities in the socioeconomic or socio-political context [20;21].

Soviet historians did not conduct special studies, entering the problem field of historical urban studies. But that does not mean the absence of urban studies in the USSR. A separate area of urban studies, demonstrated the diversity of urban development and replaced urban research in the Soviet Union, was the concept of a socialist city [22].

This concept developed by Soviet urban planning theorist N. A. Milyutin, exerted a decisive influence on the research and development of Soviet cities, starting from the 1930s. In the postwar period, there was the transfer of socialist city ideas ("Sotsgorod") in the People's Democracies. The concept evolved during the 20th century, but the main idea remains the same: to achieve financial and social equality in the city. Social equality, that was standardization and regulation of urban consumption of goods, should be ensured on an equal basis with the smooth operation of public transport and the supply of drinking water to the population.

The socialist city concept has been designed to solve the same problems that were considered by Western urbanists: to create favorable conditions for the distribution of population; to meet their needs in the residential, cultural services and social communication; to minimize social conflicts. First of all, a socialist city should have a place as close as possible to the labor settlement of industrial facilities i.e. to jobs, in the shortest possible time and with minimal costs, but with the greatest possible convenience.

The result of urban policy of "socialist city" was the emergence of cities that meet all these requirements, but the key feature of the socialist city was ignoring the individual characteristics and needs of population in specific Soviet cities, their historical development and the surrounding landscape.

Due to a lack of time, the selection of sites for districts in relation to industrial buildings was carried out without the long-term measurements of the wind rose, the number of water sources and their quality. In terms of districts construction the priority was given to visual harmony and ease, rather than rationality. Construction of streets and roads was carried out without regard to parking spaces required for all vehicles that these streets and roads can accommodate. Placing social objects did not take into account a real demand on the population of the city or district. Passenger traffic of public transport focused on the connection of the region with the city 
center and the main enterprise, which employs residents of the region, while the inter-regional connections were not established.

Changes in the Russian socio-economic system led to the aggravation of all these shortcomings. Houses of Culture, built in Soviet times, came to desolation, and cases of their conversion within the urban space were a rarity. The places of people's attraction changed in the cities, but the public urban transport could not reorient and began to decline. Road infrastructure, despite the apparent sufficiency, was not prepared to increase the number of private cars.

Methods of urban studies in the Western pattern were not applied in planning and development of Soviet cities. Therefore, the modern inhabitants of post-socialist cities have to not only minimize the direct impact of industrial construction (environmental pollution and disposal of vacant industrial sites), but also expend resources for the elimination of many errors that occur from the use of the Socialist city concept.

\section{Conclusion}

Modern Russian city arose in the transition between the successive political regimes and different types of socioeconomic relations. Historical urban studies involve the study of the processes in the cities that are relevant and problematic, but this methodological resource in the study of Russian urban space is now only partially involved.

The methodological complexity of solving the issues of historical urban studies is that the emergence of urban issues that require scientific judgment is fluctuating in nature. The imbalance of the urban development or an uncomfortable increase in population density at a certain point, is usually due to the lack of integrated solutions of various socio-economic difficulties at the past stage of formation of urban space. In addition, the formation of cities and foundation for their modern development took place in different historical periods under very different circumstances: it was without taking into account scientific development of those problems, which have acceded to solving problems of cities at the later stages.

The problem field of historical urban studies is vast and very promising for a modern Russian researcher:

- The identification of historical factors that determine the position of the city in the hierarchy of other cities, as well as the efficiency of resource accumulation for the successful development of cities demographic, economic and infrastructure. Search of reasons for the explosive growth or the inevitable degradation of individual cities.

- Modeling schemes of social interaction in the urban environment in accordance with its economic orientation, social systems and strategic importance in specific regional and historical realities. The diagnosis of the compliance level of the urban infrastructure and the pace of economic and social processes taking place on its territory.
- Establishing the degree of intensity and the radius of influence of the city's economic and social development on the surrounding rural areas.

The set of the circumstances and conditions of formation and functioning of modern Russian cities requires scientific studies using the experience of Western historical urban studies, in particular methodological tools of the Chicago School of Sociology. Changing the external characteristics of the city as the aggregate results of its population activities, there should be a study showing the city from the inside, as a social and infrastructural organism.

\section{References}

1. L. Fernandez, Journal of urban history, 41(4), 566571 (2015)

2. C. Nicholson, Series Historical urban studies. Slovo, 22(2), 125-126 (2010)

3. D.Ya. Rezun, Essays explored the history of the Siberian city: the 18th century (Novosibirsk, 1991)

4. A. Mazanik, Urban History, 42(3), 509-520. (2015)

5. H.T. Graef, Zeitschrift fur historische forschung, 41(3), 450-451 (2014)

6. V.V. Ageeva, I.A. Ageev, A.M. Nikolaeva, Z.N. Levashkina, The European Proceedings of Social \& Behavioural Sciences EpSBS, VII, 167-172 (2016)

7. V.P. Zinoviev, Siberian historical research, 2, 33-41 (2013)

8. P.P. Rumyantsev, Bulletin of the Tomsk State University. History, 1, 18-21 (2010)

9. X. Meng, Science, 343(6167), 138-139 (2014)

10. P. Capobianco, Cultural Geographies, 23(1), 174175 (2016)

11. V. Das, M. Walton, Current Anthropology, 56, 44$54(2015)$

12. V.P. Zinoviev, Bylye Gody, 29(3), 42-46 (2013)

13. I.A. Ageev, V.V. Ageeva, Procedia - Social and Behavioral Sciences, 166, 24-29 (2015)

14. C. Evans, Planning Perspectives, 30(1), 165-170 (2015)

15. P. Hadfield, Urban Studies, 52(3), 606-616 (2015)

16.E.W. Burgess. The urban community: Selected papers from the proceedings of the American sociological society (Chicago, 1927)

17. M. Weber, The city. (Free Press, 1966)

18. K. Wiest, Urban Geography, 33(6), 829-849 (2012)

19. M.B. Katz, Journal of urban history, 41(4), 560-566 (2015)

20. G. Bridge, International journal of urban and regional research, 38(5), 1644-1659 (2014)

21. J. Lavrinec, Filosofija-Sociologija, 21(1), 54-63 (2010)

22. K. Ki, Journal of North-East Asian Cultures, 1(34), 469-488 (2013) 